in most of these serious cases, after the recovery of the patients from the complications, the perforations gave very fittle trouble. Some of them healed, and this was no doubt due to the drainage which had existed for some time. By no means, however, did they all heal in the uniform manner that was observed in children; but of those that did not, many fell into a state of marked quiescence, so marked with some that they became dry perforations. By this term " dry" I mean when not only no moisture is present, but when not even a trace of inspissated pus can be detected. Now this condition of a dry perforation has for many years been a matter of wonder to me. I can understand a perforation being dry for a few years, but I constantly see people with a complete history of how the perforation took place, and yet no knowledge of discharge for periods of twenty years and more. If ever the old proverb of "let sleeping dogs lie" was of practical application, it is in the case of a dry perforation, for the very slightest interference will bring back a discharge which may last for even the remainder of a life; and this is why I wonder how such slight irritation is avoided in ordinary life for so many years. A little water getting into the tympanum is often enough to excite suppuration. Bathing in the sea will always do it. Numberless times I have known it done by a person either getting his ear syringed or syringing it himself.

This extraordinary susceptibility was once brought most forcibly to my mind about the spring of 1876. A gentleman thirty years old, having been deaf with one ear since he had scarlet fever as a child, thinking himself rather more so than usual, came to me for advice. The ear was filled with cerumen, and I removed a plug by gentle syringing. There then became visible a large perforation in a dry quiescent state, from which there had been no discharge since childhood. No discomfort of any sort followed the syringing, and the hearing was improved to its wonted state. I have no doubt that a dry plug of cerumen had formed a natural protection to the tympanum. Some days after this he crossed the Channel in rough weather, and was, whilst on deck, drenched by the spray of a wave breaking. Some of the sea water got into the ear, and shortly after this the ear began to discharge; there was profuse suppuration; a rigor followed, and he had empyema, the result of septiciemic poisoning. The pleura was tapped, and he happily recovered; but I always remember this case whenever I see a dry perforation. The folly of persons in putting every conceivable fluid into their ears is very great, and the rashness of those who without due thought suggest it is considerable; but the fact remains that for dry perforations nothing better is yet known, I believe, than a masterly inactivity, and that for them, at any rate, the limits of aural surgery have been reached when they have been discovered.

I observe in the two papers on Disease of the Mastoid in the Transactions of the Royal Medical and Chirurgical Soeiety (one $I$ have already referred to) that $I$ made no mention of two or three conditions. One is that in which the mastoid cells become inflamed and suppurate without the tympanic cavity being at all involved. The membrane is therefore entire and the hearing good. This state of things is not at all common; and when I have seen it I have failed to find out its origin, except when it appeared traceable to a blow. Another is when the mastoid cells in very aged people have suppurated in the usual nanner, but with this difference, that the process extended over many months insteal of days or weeks, and that there never was any severe pain, even up to the time when an opening was made. A third condition is simple periostitis of the mastoid in children, which nothing but a free incision succeeds in removing permanently and completely.

National Health Society.-The Duchess of Westminster on June 29 th distributed, at the Town Hall, Westminster, the certificates awarded, after the examinations on domestic hygiene, sick nursing, and first aid to the injured, under the auspices of the National Health Society. There was a large gathering, the prizewinners being, with very few exceptions, ladies. Spencer Wells, who presided, said he desired, on behalf of the medical profession, to express the great interest they had always evinced in the important work of the Society. Resolutions were passed affirming the necessity of increasing the funds of the Society with a view of widely extending the area of its operations.

\section{d afreture}

ov

\section{DISEASES OF FAULTY HABIT.}

By J. F. GOODHART, M.D., F.R.C.P.,

PHYSICIAN TO, AND LECTURER ON PATHOLOGY AT, GUY'S HOSPITAL.

GENTLEMEN,-As a natural outcome of what I have said in a former lecture upon the relationships of morbid anatomy and pathology, ${ }^{1}$ we will to-day consider Faulty Habit in some of its many aspects.

Now, bad halits have roots of considerable length, which crop up in many a pathological process that would not, perhaps, occur to you; and it is not difficult to show that albeit to cursory glances the subject might be estimated as " unpractical," it is nevertheless one that presses, by the frequency with which diseases of its kind occur, and by the want of intelligence with which the treatment of the results of bad habit are handled. What is a habit? I have said before that we are sometimes killed by the perfection of our physiology, and I am now intending to give further proof of that proposition. From a physiological point of view, well-ordered habit is the means by which we live. Expressed in short, it is automatonism. All tissues have certain functions to perform; and if we trace the development of these, we find that in all there is a preliminary stage of hesitation and of imperfect and laboured action, which gradually under the process of education becomes less and less so, until at last the stimulus provokes a definite and constant result with certainty. Having already developed this idea as regards the rudimentary cell units of animal life, this may be taken as sufficient recognition of the existence of a reflex arc from stimulus to response, in such rudimentary forms of life as simple protoplasm - that is to say, independently of a nervous centre, or at any rate of any differentiated one. And for our further purpose we will take the more complex organism and express or define habit in terms of reflex action. Reflex action is a natural physiological one, but all reflex action tends to become over-perfect. A certain stimulus finds its way along one or other particular nerve strand to a centre, and then provokes it to a particular response. The next time the arc is traversed the result comes more easily, and so on, until the stimulus has passed so often that the centre works constantly and readily. But when does disease step in? When the perfection of the working is detrimental to the organism, either in its own person or in its relation to its environment. As the "antocrat" puts it, habit "is a confession of failure in the highest function of being, which involves a perpetual self-determination in full view of all existing circumstances." And inasmuch as all the more complex activities of man are due to an elaborate mechanism of refiex centres, controlled by a central bureau, many of the diseases of faulty habit come to be reflex action out of touch with this bureau : the check action is at fault, and round goes the spring until it is exhausted. Two illustrations occur to me which can hardly be called diseases, and which are yet, to my mind, very instructive, as illustrating this passage of physiology into pathology.

Take the one the most familiar to us: written speech and its faults. The art of writing is acquired by a slow and very laborious process. There is no need to recall this to the memory of anyone. Watch any child learning to write, and you will see it in all probability with its tongue out or its face contorted, clutching the pen like grim death, and all its movements indicative of exertion. And as a further evidence, valuable at this time of life, it very soon tires of a lesson of this kind. Time flies and facility comes with the practice, and if a man have not too much writing to do, or has plenty of time in which to do it, he may still continue to write well, although after a time he has little conscious control over the formation of individual letters. He sets the machine going, and it goes. If, however, a man have much writing to do and inadequate time, subjectively or actually, his writing reflex oradually becomes more rapid, the letters run one into the other, and 
he writes a short hand which is a perfect expression of automatic action on the part of the writing centre, but which is a very imperfect one as regards its utility and power of communication with the external world. Dill you ever think before of illegible writing being an expression of disense? Alienists are fond of studying the handwriting, and find in it valuable symptoms of various mental conditions and of the power of muscular control. But my present contention is a wider one than that: it is that Illegibility, inasmuch as, and in so far as, it is the expression of perfect and automatic action, is a disease; it untits the organism in some measure for its environment, as do several other conditions that I shall have to mention. And it is probable, too, that there is a similar state of things for speech. It is not so easy to trace the various stages in the individual; but we meet with speakers of the most varied rapidity, from the man who enunciates with much deliberation and precision to the one who unites indistinctness will rapidity, and whose utterance is mostly lost in a lingual shorthand, so to speak. And then there is the man-such a one has lately been in Philip ward, - but not by any means uncommon as age advances, who has become quite unintelligible, whose inflexions of speech are all lost and words run one into the other, in what, if represented by the graphic method, would be but a tremulous line.

One other example I will adduce-that of the man who walks quickly, and more quickly, until in the course of years his pace takes a constant mongrel trot. These are not very conımon, but I have known one or two. I could point to one now in the suburbs of London who is well known in his district. He, no doubt, did a fair heel-and-toe at one time; he would certainly not be allowed in a walking match now. I can fancy the neurologist eyeing him with interest and muttering " Where is his lesion?" But I renture to contend that no lesion exists. The central ganglia which control his pace have simply gone on unto perfection, and that man is an illustration of functional development.

Now the hypothesis of the gradual evolution of function applied to the nervous system explains many a case of insanity. If the tendency be to evolve or develop along such lines as are most used, it is obviously of inmense importance that as many lines as possible should be opened up and developed, otherwise those in use will be overfrequented, and the roadway will either fall ont of repair or become so macadamised that the journey of thought is made with no conscious perception of its purpose. By passages of this kind memory is not stirred, mental association and activity are not awakened: the function is automatic; a machine could produce an equally goor result. And single-line brains supply a fair proportion of insanity. Here is a common type: Picture to yourselves a lady (of the pre-high-school period) of the ordinary run as regards accomplishments, and with just enough permanent income to enable her to live without the necessity of gaining a livelihood. She is one of a family of, and she herself has imbibed, a strong religious bias. She never marries, and Ell her life, up to fifty-three or fifty-four years of age, her chief sources of mental exercise, save what little is obtained from a by no means active intercourse with friends, are derived from the study of her Bible and volumes devoted to personal religion. Thus the history of such a life-and the type is, alas! pitifully common-is one of few stirring duties, of no sustained effort, of nothing that can be called in our present use of the word "education." A brain of this kind is worked almost entirely on one or two lines, and, good as these in themselves may be, it has wanted variety, just as the stomach wants, and will have, if its work is to be done properly, a variety of food. In its absence you can predict the result. The poor patient passes her later years in an asylum, a sufferer from religious mania, the natural outcome of this macadamisation of one or two roadways of thought, and the consequent grass-grown obliteration of all the rest.

Take another case as an illustration of the value of this line of thought in the treatment of such moods. A young man came to me one day in a state of extreme mental depression. There was a very strong family history of insanity in his case; he had been working hard for an examination, and had become overwrought and depressed. In consequence, he was convinced that he was going ont of his mind, as his relatives had done before him. What was to be done? To shrug one's shoulders and sympathise with him would be but a thinly veiled recommendation that in his leisure he should visit some of the surrounding lunatic asylums in order to see which looked the most comfortable and enjoyable. He must see through that in a second or two. I talked physiology to him instead. Admitting his facts, I could honestly minimise their meaning. I did not think so mucl of the family history as he did, not being a believer in a foreordained insanity for anyone. Heredity does not count for nothing by any means, but lunacy in the family is no more than the gout that has been passed on by the unconscious good fellowship of a grandfather. Either is a thorn in the flesh which may buffet at any time if a man is not careful; but with care we may be in great measure the masters of our own destiny. A man with insanity in near relatives I regrard as one who has a sniall amount of reserve capital at his bankers. But, as has been well said, it is just those whose capital is small who need to choose the best investments, and thus I said to my friend: "You can be a madman if you choose, or a sane man either, just as well as anyone else. A madman a little more easily perhaps than some; a sane man by a little harder work or care. If you cherish the idea that you came into the world for the express purpose of becoming a lunatic, you will of a surety fulfil what you assume to be your mission. If, on the other hand, you realise that insanity is in a large measure the result of faulty education, of ill-regulated indulgence in the lazy licence of freedom from the trammels of any laws of thought, and go and live your life in strict accord with that conviction, never overworking yourself, but giving your mind free play in as many healthful directions as possible, you need not fear." That may be some ten years ago. I have seen him several times since, and mentally he has never flagged. It is to my mind terrible to see this widespread horror of insanity. Even the most trustful and religious regard it in a way that, if they could only reason about it, they would see was the making it a matter of blind fate. A relative goes out of his mind, and henceforth his name is hardly mentioned as a member of the family, and the hospital in which he is placed--I do not like the word asylum, - so far as the family is concerned, might as well have been his grave. But a common-sense view of the pathology of insanity sees little that is dreadful save the wreck of mind. There is nothing more dreadful truly than the noisy improprieties and the vacant face of one who has been known to us when of intelligent mien. But, apart from this and from the special difficulties of management, there is nothino else in madness to excite our dread. Fur when we deduct the madness of accidental disease - that due to disease of the vessels, of the membranes of the brain, and so on, - that form of insanity which comes of faulty education, a local and preventable factor, assumes such a frequency and importance that hereditary tendencies are quite suborlinate. Mind, I do not say they are unimportant-it must be allowed that occasionally they do apparently lead to a sudden explosion, even in such as have invested their brain-power well, - but that these cases are few, the others the many, I verily believe.

Thus far I have chiefly alluded to disease as due to a habit of thought produced by allowing the mind to run too much in one groove. I might have given several other instances than that I have done. There is, indeed, the common case of the hypochondriac, whom all must have seen. Нypo. chondriasis may be seen any day in one or other of its many phases. There is the simple depression of spirits and thought for ills that have no existence, that are not within the horizon even of an unjaundiced vision, and that are dispersed at once by cheery companionship or resolute occupation. There are the varied types, generally dyspeptic in some measure, with the careful scrutiny of the diet sheet for the next meal, and the verdict beforehand that it will certainly disagree, up to the most extreme self-consciousness that ends in self-destruction. Such people go mad simply because they give in to the bad practice of indulging a faulty habit of mental exercise. If they would but let themselves alone, earn half-a-crown a day by work which they really give good heed to, and live upon it, live in fact and in deed for others, and not for themselves, it would be, in truth, to live for theniselves in the best possible way, and the remedy for many a case of incipient madness.

But it is, as I have said, equally a physiological law that, whereas such parts as are used or used overmuch tend to increase in size and power of function, so those parts that go unused tend to become rudimentary. And to rudimentary brains of this sort another large element of insanity 
is due. I was once walking in the Derbyshire dales, and, wanting to get to one of the mines, we asked our way of a rustic swain at work in a neighbouring field. There was every reason to suppose that we were quite near our destination, but this poor fellow was quite unable to direct us, although he had all the appearance of being a native of that part. It turned out, as we had supposed, that we were quite near our journey's end-in fact, the mine was under the very hill on the side of which the man was at work. By climbing the hill and dropping down on the other side we were there in no time; but the ordinary route would have been somewhat circuitous. Telling this one day to a friend, he told me that he knew of an old woman past seventy, living in a small town, who had never once in the course of her life gone outside it, and such cases are by no means uncommon. Now what I want to to ask you is this: What kind of mind can such persons as these have in comparison with those who go about and have intercourse with their fellows, even the best of them, and allowing that the best of them-perhaps a fair proportion of them-do take in a marvellous amount from the attentive observation and common-sense reflection upon a very contracted field of thought? The duller brains, succumbing to their circumstances, the sport indeed of such, can have few ideas beyond those begotten of mere animalism, the radiations from the primary necessities and impulses of nature, of eating, sleeping, and the continuation of the species. Can one wonder that a brain like this is superstitious, may be brutal upon occasion, is at best swayed much by emotions of low standard? Can one wonder that, where the conditions are so adverse to mental grow th and exercise, impulsive insanity, acquired imbecility, are occasional results? One wonders rather that such an outcome, natural as it is, is not more frequent. But there is no need to limit the possession of a rudimentary brain to any one district or stratum of society. Everyone knows how common a fault any where and every where is that of allowing the brain to lie fallow or half stocked in the midst of abounding opportunities. And what right therefore have we to make so much of hereditary defect? A congenitally dull brain, a slowly responsive brain, a too easily tired brain, an excitable brain, should never be regarded as so many "makes for" insanity, but rather as so many opportunities for studied training, for skilful guidance into well-regulated and well-ordered habit.

But I have not yet done with the brain; there are other diseases of faulty habit which I would yet like to mention, and the first is epilepsy. Here, again, the tendency is to think the peccant organ the victim of unkindly fate. An individual has a convulsion, and probably the first question that will be asked you is: Is it epilepsy? And why? Because if it be, then fitfulness becomes, it is thought, the main spring and order of the sufferer's being. I would try to combat such a notion with determination. It is true, unfortunately, that it is often so. Nevertheless, we may always hope against it, and on this very hypothesis of habit which I am now labouring to impress upon you. And there are one or two points about convulsions that are worth attention in this light. Eclampsia may arise, of course, from various causes, but such as are due to known conditions-such as tumours, syphilitic thickening of the membranes, alcoholism, lead, anæmia, and so on-we relegate to their proper cause. They at any rate are capable of explanation, and some of them of remedy. Epilepsy may be defined to be recurrent convulsion which owns no obvious cause. Now of these a certain number have their origin in infancy, and are, a very large number of them, associated with rickets. So much is this the case that it may be said with a fair amount of accuracy that the conditions of body existing in rickets beget a state of braiu which leads to sudden explosions of this kind. But if this is the case it would seem to follow that the convulsive tendency is in a great measure under control; that by preventing rickets convulsions are prevented; that by taking care of the rickety child, and preventing the occurrence of convulsions until such time as the rachitic state has been effaced by the substitution of a healthy one, there would in the end be little risk of any further convulsions. There is abundant evidence to show that this can be done by the careful treatment of such cases by appropriate remedies, and that if not-sometimes, too, it must be added, in spite of the remedies-the child has one fit, then another and another, and so on until the epileptic habit is produced, and not much can be done for its complete abro- gation. Therefore, when a child or an adult has a first fit, after excluding all possible causes, do not call it epileptic, but speak for the comfort of the patient and his friends in physiological language: epilepsy is a habit. One swallow does not make a summer, and the occurrence of one convulsion does not constitute epilepsy. One fit having occurred, it becomes our earnest business to try to prevent the onset of any more. But there is no inborn necessity of this in the mere fact of the having had one. But every additional fit makes another the more likely, until at last a habit is formed which is not easy to control. I will further add, in conformity with what I have already said upon the effect of habit in monopolising all the trade, that the brain power of the confirmed epileptic may almost be said to run away in gymnastics, for these poor people, while ever becoming greater adepts at convulsing, if I may coin a word, correspondingly decrease in mental power, until they become hopelessly imbecile. And may I pause for one moment just to say that it has several times occurred to me that this running away of intellectual power is sometimes visible in the great athlete. I do not, of course, mean to class athleticism and epilepsy together as coequal, for it is obvious that the phenomena of convulsions are particular, and specially adapted for the destruction of brain power, by the coma that is part of the process. But what I do mean to say is, in pursuance of the idea of correlation developed in the former lecture, that it is only the exceptional man who can be at the same time a great athlete and a great genius. I am sure that the study of the physiognomy of any large number of those who devote themselves to the excessive culture of muscular Christianity will often show that for the time being there is a distinct deterioration in that dignity of mien which betokens the man who is obedient to the physiological law, "moderation in alk things."

Let us take now a minor mental ailment or bad habit what I will call inconsequence of thought. At its worst it is insanity, and no doubt about it; but in its earlier or milder phases it is the direct outcome of a faulty educa. tion of the mind; it is often the result of indulgence in mental sloth, and one may well suspect that, could we but trace back many a rambling dementia, we should see its origin and slow accentuation in and from some such early and at first trifling fault. To arrive at a logical habit is most laborious mental process to the great majority of minds, and but few men in comparison to the multitude attain it; and, like all the complex habits in which the hand soon loses its cunning for want of practice, the logical habit, unlike the more rudimentary tricks, unfortunately, soon blunts of its keenness, and it may be said to require a lifetime of labour devoted to its service. The possessor of such an article, however, might well pride himself on being a great mental surgeon and anatomist, for his skill in dissection is indisputable, and the instrument with which he works is a weapon of the finest and the coldest steel.

Another bad habit easily cultivated and very common is drowsy-mindedness. Take it as actual sleep, its most extreme form, and it is by no means uncommon. Natural sleep is only a habit. Much has been written about it and its peculiar punctuality. But there is nothing wonderful in sleep when once the organism has been commissioned with what we may still call the "principle of life." It has been well said that all nature sleeps; and so it does, each organism after its own fashion. The amoba has intervals of rest between the outputs of fresh processes, and these are sleep to it. The breast and the uterus have their rest, a long sleep that sometimes ends in death of function, which is their life, by having been too long. The heart has its diastole, a twelve hours' sleep in snatches; it wants and has no other. The sleep of the upper nervous system is a temporary insensibility, a cessation of its functions, so much for so much work, an absolutely ineradicable habit engendered by ages of custom. What else could it be? The cessation of the function of thought is sleep; the other characteristics are secondary and obedient even unto death. And, as a habit run to excess, sleep can by some be so much indulged that there is practically little limit to the duration to which it may extend. Try it anyone for himself-at any rate, such as are of the sleeping habit, for I shall have to speak directly of the opposite of this-viz, the habit of sleeplessness. Make a point of taking a nap after dinner for a few days, and see how much resistance will be requisite the first time you renew your accustomed activity, unless the in 
clination is counteracted by some occupation of preponderating exhilaration or interest. Sleep late into the morning - sleep at any time-cultivate a general drowsiness, and there are, I say, a large number of us who could with ease so develop the habit as virtually to sleep twelve, fourteen, or sixteen or even more hours, with practically no intermission of the state. But I am more concerned to insist apon a state of sub-sleep than this, a prolongation of natural sleep. For one such case as the latter, there are hundreds of the Pickwickian Joe type passing through life half asleep-that is, not thinking. Or, like David Copperfield, his thoughts not intent upon his calamity, " but idly loitering near it." A thought comes into the heads of such occasionally, and tickles the brain for a few seconds into a few fitful sparks, but the best part of the wakeful hours is spent in "mooning," they could not tell you any definite purport in their thought. This is a bad habit, and too readily indulged by all of us, for the simple reason that it is more difficult to keep out of than to fall into, and no doubt it rolls some minds down the hill into dementia.

One word as regards the other side of the picture-the sleeplessness I have alluded to. There are few more distressing cases to the physician, both on account of its effects on the sufferer and its obstinacy, than this. But I want to point out that there are two classes of cases of sleeplessness. There are first-and I think most important for the due apprehension of the second class-those who habitually have no more than three, or at the outside four hours' sleep, and, what is more particularly the point, who thrive upon it. People of this kind do not make anything of it, and rou only find it out in casual intercourse. And the other class who come and complain, and want treatment, as a rule get quite as much sleep, but because they do not get what is the natural allowance of six or seven hours at a stretch they worry about it. But if you go into the history of these cases you will almost invariably find that they have always been light sleepers; in many cases their parents, or one or other of them, have been so before them; and it is the habit of their nervous system to sleep in snatches. And if you can only make them understand that this is so, that in their case the brain is like the heart in the matter of its sleep, and like the heart will do as well if they let it take its own way, a snatch sleep of this kind is not a serious thing-let my former group of cases bear witness. Nevertheless such cases are serious, not because of the sleeplessness, but because, deeper than that, the rhythm of the brain is inherently bad. These patients are neurotics; their ancestors in many cases very much so before them; the habit of brain is faulty by inheritance, and has become still more inveterate by faulty education and the inexorable friction of circumstance; and the distress because of sleeplessness is one symptom of many that point to cerebral malnutrition. There is another neurosis of which all that I have said of insomnia might be said-I think with nearly equal point: the singing or other noises in the ears that go under the mame of Menière's disease. There are those who suffer and whose mental action is robust and independent enough to put it aside as no more than an inconvenience. There are others, and more numerous, who go from one doctor to another seeking relief and finding none. These people take all the medicine that the various Pharmacopoias of this country and of that can offer, and not only do the majority obtain only very transitory relief, but for the many every fresh failure is an additional element making for a total wreck.

Again, morbid sensitiveness to trifling subjective sensations is a faulty habit. I saw the other day a poor old man who had spent his all, over $£ 300$, he said, in an attempt to relieve himself of an itching skin. A sensitive skin in one way or another is a common thing. We all know the man who is afraid of draughts, and how unpleasant he can make himself; the man with pruritus is less objective. But take a case of this kind, one who is subject to itching or to formication. If he give way to either, the sufferer will tear himself into a state of the most abject misery, or spend his days a victim of general creeps and crawls, which is but too likely to end in a state of mental dejection. These feelings come to all more or less-sufficiently so, indeed, that all may know by their own experience that sensations of this kind can be, and must be, controlled at their onset, or woe betide us. Quite as much could be said of pain. The conscions direction of attention upon any pain, however slight, for a length of time will gradually make a trifle unbearable, and even apparently agonising. And there is many a sufferer whose sole ailment is thus generated, and whose successful treatment is to be compassed, not by drugs directed to the symptoms, but by lifting the nervous centres ont of their monotonous and now customary groove. This is no easy task, but the moral of it is, when concreted down into a practical application-There is no drug for chronic neuralgia that is equal all round to cod-liver oil.

But time flies, and not a tithe of the diseases of faulty habit have been mentioned. I might instance incontinence of urine in children and chores as other good illustrations enforcing much of what I have already said, for there are few diseases from which medicine obtains less credit. Random firing seldom scores a bull's-eye. But I have spoken of these elsewhere, and there are one or two other common seats of disease where faulty habit enters largely into the cause, and is indeed the all-important element to recognise in dealing with it successfully. These are the uterus that aborts time after time, and the stomach in chronic vomiting. Both are muscular organs, and the mechanism of the expulsion of their contents is much the same for each. In both sorne local condition may be at fault, but the organ is worried into a contraction at the wrong time, the disordered rhythm repeats itself over and over again, and thus a habit is engendered. As regards the uterus, perhaps, one may say that few mistakes in treatment are likely, for if a woman has miscarried once or twice at a particular time, she is kept to her couch for some time both before and after the disordered rhythm is expected to exert itself, in order that rest may allay the excessive instability and restore a natural action. But with the stomach there is a wider range of conditions in which the habit is produced, and it often happens that disease is not cured because of the want of appreciation of this element of the case. Who does not know of the stomach that has vomited week after week, or month after month, and even sometimes with organic disease behind it to produce it, which has been at once relieved or permanentiy cured by attention to the muscular action from this point of view. All of you must have seen at least one or two such cases in women, and how troublesome they are to cure; but taken into a hospital, the rontine and health hunger of a hospital ward, combined with a diet which gives the nervous circuit no excuse for action, and with drugs-chiefly iron - that at the same time raise its tone, they seldom give any persistent trouble, and the romiting quickly ceases. Much of the vomiting of infancy is certainly due to the same faulty action. When the stomach is young and ignorant, it naturally becomes frightened and bolts readily. And just occasion for its bad behaviour is but too often given. Perhaps cow's milk is given on the if-you-don't-like-it-you-must-lump-it principle. A solid mass of curd is formed with which the gastric juice is incompetent to deal satisfactorily, and a slight inflammatory state is set up. The diet is altered, but still fails to suit the case, and the primary condition is increased, and thus it passes on from one of simple indigestion, that judicious starvation would have cured, into one of the most miserable and troublesome diseases of infancy-chronic vomiting. It is a like case with many of the diarrhœas of childhood-the food does not agree, the bowel is irritated into over-action, and the child has diarrhoea. Food of one kind or another is nevertheless poured in with increasing persistence because the child begins to waste - it wants "keeping up." But the frequent evacuations not only continue; they become worse until no absorption of any kind takes place from the mucous surface, and the patient dies by the faulty habit of the intestinal action; at any rate, in many a case of this sort no adequate morbid changes are to be discovered in the intestine after death. What is wanted in these cases in great part is so to feed the over-sensitive mucous membrane and so to medicate as to give the nerves and nuscles no excuse for indulging in temper-if I may put it so,-and by so doing the organ may often bè coaxed back into stable and wellregulated action. I might give you several other good examples of the part played by habit of this kind in disease. I could have shown cause for spasmodic asthma being sometimes kept up in this way; palpitation of the heart of particular kind also ; as well as some of the so-called vaso-motor disturbances that are met with not uncommonly in women. But these I must leave for want of time. What I have said will serve to direct your attention to the subject; and, this done, I am well assured you will find the ground neither uninteresting nor unfruitful. 